\title{
Modern insulins-comment on facts and assumptions in a recent Editorial
}

\author{
M. Frick • J. Knollmeyer • H. Riederer • C. Heinemann
}

Received: 23 November 2007 / Accepted: 3 December 2007 / Published online: 22 January 2008

(C) The Author(s) 2007

\begin{abstract}
Abbreviations
IQWiG German Institute for Quality and Efficiency in Healthcare
\end{abstract}

To the Editor:

Many aspects of the scientific, economic and political discussions on the benefit of new medicines, for which modern insulins are a pivotal example, resonate in the recent Editorial by Holleman and Gale [1]. In this letter we comment on some errors in this contribution and raise questions on some of the authors' assumptions. As space is restricted, we are unable to provide a comprehensive review of the evidence.

\section{Facts}

Share of analogues out of total insulin prescriptions The use of insulin analogues is significantly lower in Germany than in other large European countries [2]. In 2006, analogues made up $40.6 \%$ of the insulin prescriptions in Germany, compared with $75.6 \%$ in France, $87.6 \%$ in the UK, $61.7 \%$ in Spain, $46.0 \%$ in Italy, $91.2 \%$ in Sweden and $71.4 \%$ in Austria. In 2007, almost two out of every three German insulin patients were treated with human insulin and not analogues [2].

M. Frick $\cdot$ J. Knollmeyer $\cdot$ H. Riederer $\cdot$ C. Heinemann $(\bowtie)$

Sanofi-Aventis Deutschland,

Potsdamer Str. 8,

10785 Berlin, Germany

e-mail: christoph.heinemann@sanofi-aventis.com
Reaction to the German Institute for Quality and Efficiency in Healthcare report on short-acting insulin analogues in type 2 diabetes It is not correct that the industry did not dispute the results provided by the German Institute for Quality and Efficiency in Healthcare (IQWiG) on shortacting insulin analogues in type 2 diabetes. Sanofi-Aventis, like other manufacturers, has criticised the IQWiG assessment as being erroneous and biased [3] and the consequences drawn from it as unbalanced [4], with the detailed review provided by Sanofi-Aventis on the assessment in the public domain [3]. In addition, our company has initiated legal action against the authorities' decision to no longer reimburse the costs of prescriptions for short-acting analogues for type 2 diabetic patients. Sanofi-Aventis' decision to give rebates to statutory sick funds was made to ensure continuity of care for patients.

$I Q W I G$ reports regarding insulin analogues Holleman and Gale suggest that further to the lack of benefits of shortacting insulin analogues reported by IQWiG, similar findings are likely for the long-acting analogues.

IQWiG results on short-acting analogues in type 1 diabetes have been discussed by scientific experts in a hearing initiated by the Gemeinsamer Bundesausschuss (G-BA, [Joint Federal Committee]), the German authority responsible for reimbursement. It became clear that important benefits had not been identified by IQWiG (e.g. use in children) [5]. Regarding long-acting analogues, IQWiG recently amended its report plan, almost 2 years after its initial publication $[6,7]$, following the new law making it mandatory for IQWiG to follow international standards. The amended plan has been subject to a scientific hearing and its final version is currently pending. 
The benefits of insulin glargine in terms of hypoglycaemia The authors of the Editorial concede that there are 'limited' benefits of glargine vs NPH insulin in terms of 'a $15-20 \%$ reduction in hypoglycaemia, mainly at night'. They subsequently state that $\mathrm{HbA}_{1 \mathrm{c}}$ levels and hypoglycaemia require combined analysis. We would like to refer to a new metaanalysis on patient-level data that has examined precisely this [8]. The authors of the meta-analysis conclude that the benefit of glargine vs NPH is in the range of $25-30 \%$ for confirmed and severe hypoglycaemic events. In studies with more aggressive titration schemes, the superiority of glargine vs NPH with regard to hypoglycaemia even reaches $40-50 \%$. The same investigation also provides evidence of improved rates of symptomatic hypoglycaemia for glargine vs NPH. Because the risk of hypoglycaemia is a significant barrier to reaching target $\mathrm{HbA}_{1 \mathrm{c}}$ [9], the benefits of glargine vs NPH are obvious in this area.

\section{Assumptions}

Evidence-based medicine Holleman and Gale call for evidence-based medicine as the ultimate authority with regard to insulin analogues. They regret 'with some despair' the non-availability of double-blind comparative trials as the 'only one fully objective' way of drawing conclusions, although they state earlier in their article that these trials were often hardly possible on the grounds that NPH and glargine can easily be distinguished. We would like to draw the reader's attention to the broader definition of evidencebased medicine established by key scientists in this area. Sackett et al. point out that even when randomised trials are absent or impossible, evidence-based medicine should be applied, stating that 'if no randomised trial has been carried out for our patient's predicament, we must follow the trail to the next best external evidence and work from there' [10]. According to Haynes [11], evidence becomes relevant in clinical practice when the patient's circumstances are established, related to efficacy, effectiveness and efficiency of treatment options, and the likely consequences of each option are taken into account. Thus, the task is not to choose between eminence-based and evidence-based medicine, but to identify the best available evidence for the questions asked. To this end, there is more evidence to be considered than that provided by double-blind, randomised clinical trials alone. We propose to discuss the question of evidence for benefit of insulin analogues with pragmatic responsibility for patients rather than in the spirit of the search for the Holy Grail.

Will human insulin be withdrawn from the market? In the Editorial the authors discuss potential interest in the industry to withdraw human insulin from the market. Such a move would be unethical in light of the fact that certain human insulin formulations cannot be substituted by insulin analogues (e.g. formulations for pediatric use), and human insulin remains an important element in the therapeutic portfolio of physicians. We hereby would like to confirm the commitment of Sanofi-Aventis to supplying the full range of human insulin preparations to the German market in the practically foreseeable future, in the interest of patients and caregivers.

Price and cost of insulin therapies Holleman and Gale suggest a 'resolution that drug prices should be linked to evidence of benefit', implying that the higher price of glargine vs NPH (in the presence of low benefit, according to their view) is socially unacceptable when resources for healthcare are limited. They suggest that prices of analogues should be equal to that of human insulin.

We profoundly object to this route of reasoning - the cost of a chosen therapeutic intervention is not reflected by the public price of one of the employed drugs. Specifically in insulin-based therapy, resource utilisation includes additional factors, e.g. blood sugar monitoring, injection devices and needles, physician visits, rebates. If such factors are taken into account, pharmacoeconomic studies in the German context reveal that glargine-based therapies are cost-equal or even cheaper than human insulin regimens at today's price level [12].

Duality of interest The authors are employees of Sanofi-Aventis Germany.

Open Access This article is distributed under the terms of the Creative Commons Attribution Noncommercial License which permits any noncommercial use, distribution, and reproduction in any medium, provided the original author(s) and source are credited.

\section{References}

1. Holleman F, Gale EAM (2007) Nice insulins, pity about the evidence. Diabetologia 50:1783-1790

2. IMS MIDAS Quantum (2007) Available from http://www.imshealth. $\mathrm{com} / \mathrm{web} /$ product $/ 0,3155,6457606863872702 \quad 71228109$ 71461314,00.html, accessed 17 December 2007

3. Sanofi-Aventis (2007) Available from http://www.sanofi-aventis.de/ live/de/medias/E0C5B570-5157-43B6-AD84-FC60070C0E65.pdf, accessed 17 December 2007

4. Press release as of 18 July 2006. Available from http://www.sanofiaventis.de/live/de/de/layout.jsp?scat=4FF07164-DC21-4E4D-8E42EEA2C584B96E, accessed 17 December 2007

5. Nuber G (2007) Insulinanaloga bei Typ-1-Diabetes verordnungsfähig? Diabetes Journal 56:22-23

6. IQWiG (2007) http://www.iqwig.de/download/Zeitplan_A0501 Langwirksame Insulinanaloga zur Behandlung des Diabetes mellitus_Typ_1.pdf, accessed 17 December 2007 
7. IQWiG (2007) http://www.iqwig.de/download/Zeitplan_A0503_Langwirksame_Insulinanaloga_zur_Behandlung_des_Diabetes_ mellitus_Typ_2.pdf, accessed 17 December 2007

8. Mullins P, Sharplin P, Yki-Järvinen H, Riddle MC, Häring HU (2007) Negative binomial meta-regression of combined $\mathrm{HbA}_{1 \mathrm{c}}$ and hypoglycemia across eleven phase III and IV studies of insulin glargine compared with NPH insulin in type 1 and type 2 diabetes. Clin Ther 29:1607-1619

9. Davis S, Alonso MD (2004) Hypoglycemia as a barrier to glycemic control. J Diabet Complicat 18:60-68
10. Sackett DL, Rosenberg WMC, Gray JA, Haynes RB, Richardson WS (1996) Evidence-based medicine: what it is and what it isn't. BMJ 312:71-72

11. Haynes RB, Devereaux PJ, Guyatt GH (2002) Physicians' and patients' choices in evidence based practice. BMJ 324:1350

12. Janka HU, Högy B (2007) Economic evaluation of the treatment of type 2 diabetes with insulin glargine on the basis of the LAPTOP trial. Eur J Health Econ. DOI 10.1007/s10198-0070057-2 